\title{
Comparative study of glass and antimony electrodes for continuous oesophageal $\mathrm{pH}$ monitoring
}

\author{
Y Vandenplas, R Helven, H Goyvaerts
}

\begin{abstract}
Oesophageal pH monitoring data are influenced by numerous patient or technique related factors, or both. In this study, data recorded with glass microelectrodes or antimony electrodes, both with external cutaneous $\mathrm{Ag} / \mathrm{AgCl}$ reference electrodes, connected to two different recording devices are compared. Pearson correlation coefficients regarding the reflux index (\% of the investigation time with a $\mathrm{pH}<4$ ) ranged from poor to excellent $(0.55$ to 1.00$)$. Differences in data recorded with glass electrodes are not significantly dependent on the recording device (r:0.93 to 1.00 for the reflux index). The correlation between data simultaneously recorded with antimony electrodes is lower, although not significantly different for the reflux index (0.90). Correlation between data recorded with glass and antimony probes is rather poor $(0.55$ to 0.70$)$. Therefore data recorded with antimony electrodes cannot be compared with those recorded with glass electrodes. The mean $\mathrm{pH}$ recorded with glass electrodes is lower than that with antimony probes.
\end{abstract}

Ambulatory continuous oesophageal $\mathrm{pH}$ monitoring is being used increasingly for diagnostic as well as research purposes. A flood of recent publications has focused on the influence of patient related factors on the incidence and duration of gastro-oesophageal reflux episodes. There have been few studies on technical aspects of $\mathrm{pH}$ monitoring. ${ }^{1}$ Glass electrodes were shown to be superior to antimony electrodes in an in vitro study' ${ }^{2}$, nevertheless, antimony electrodes have been advised for paediatric use. ${ }^{34}$ 'Monocrystalline antimony electrodes are becoming more popular. They have the advantage of small size and therefore comfort and ease of insertion together with low cost." ${ }^{4}$ The most commonly used $\mathrm{pH}$ probes in The Netherlands are the monocrystalline antimony electrodes (Synectics Ltd, Sweden). ${ }^{35}$ As a consequence, they are often used in children. ${ }^{6} \mathrm{Up}$ to now there has been no clinical study comparing data recorded with different recording devices and different electrodes. This study investigated whether differences in data recorded with different electrodes and different recording devices are relevant for examinations performed for diagnostic purposes.
Methods

PATIENTS

Continuous oesophageal $\mathrm{pH}$ monitoring is a routine investigation in our programme for detection of infants at risk for sudden infant death syndrome (SIDS), since there is evidence in the published reports that respiratory distress and apnoea can be related to gastro-oesophageal reflux in infants. ${ }^{78}$ Polysomnography was performed at the parents' request because of their anxiety regarding SIDS. Parental consent was obtained to perform a 'double' $\mathrm{pH}$ monitoring in 130 infants. All were aged between 2 weeks and 4 months.

\section{MATERIALS}

Two different types of recording system were tested: five Digitrapper MKII (Synectics Medical) and eight Memolog 2a-600 (Scan Detectronics) devices. Both systems are solid state recorders. The recording systems do not register the continuous $\mathrm{pH}$, but samples are taken every $7 \cdot 5$ seconds for the Memolog and every 4.0 seconds for the Digitrapper. The system specifications are given in Table $I$.

Two types of electrodes were used: 15 MI-506 flexible glass microelectrodes (Microelectrodes Inc) and 20 antimony electrodes (Synectics Medical), both with an $\mathrm{Ag} / \mathrm{AgCl}$ cutaneous reference electrode. The diameter of both electrodes is comparable ( 1.2 to $1.6 \mathrm{~mm}$ ), as is the $\mathrm{pH}$ range ( 1 to 13 for the glass; 1 to 10 for the antimony electrode). The response time, which is the time needed to reach $98 \%$ of the $\mathrm{pH}$ of the calibration fluid, is 10 to 45 seconds for the glass and $<30$ seconds for the antimony probe. Calibration was

TABLE I Comparison between memolog 2a-600 and Digitrapper MKII recording devices

\begin{tabular}{|c|c|c|}
\hline & Memolog & Digitrapper \\
\hline $\begin{array}{l}\text { Dimensions }(\mathrm{mm}) \\
\text { Weight }(\mathrm{g}) \\
\text { Sampling rate } \\
\text { Memory size (k bytes) } \\
\text { Electrodes } \\
\text { No of recording channels } \\
\text { Symptom marker } \\
\text { Display }\end{array}$ & $\begin{array}{l}156 \times 150 \times 42 \\
1054 \\
7 \cdot 5 \text { or adjust } \\
192 \\
\text { Glass } \\
1 \text { or } 2 \\
\text { Push button } \\
\text { LCD, pH event } \\
\text { marker, no of } \\
\text { registrations }\end{array}$ & $\begin{array}{l}155 \times 90 \times 33 \\
300 \\
4 \cdot 0 \text { or adjust } \\
24 \\
\text { Glass or antimony } \\
1 \text { or } 2 \\
\text { Push button } \\
\text { LCD, pH }\end{array}$ \\
\hline $\begin{array}{l}\text { Power supply } \\
\text { Calibration } \\
\text { Automated data analysis }\end{array}$ & $\begin{array}{l}\text { Batteries } \\
\text { Pre and post } \\
+\end{array}$ & $\begin{array}{l}\text { Batteries } \\
\text { Pre and post } \\
+\end{array}$ \\
\hline
\end{tabular}

$\mathrm{LCD}=$ liquid crystal display
Janssen Pharmaceuticals, Beerse, Belgium

Correspondence to: Dr Y Vandenplas, Academ Children's Hospital, Fre University of Brussels, Brussels, Belgium.

Accepted for publication 20 August 1990
Hospital, Free Universit of Brussels, Belgium Y Vandenplas 
performed with the fluid provided by both companies (calibration fluid for the glass electrode: $\mathrm{pH} 1.68$ and 7.00 delivered by Scan Detectronics, Radiometer, Copenhagen; fluid for the antimony electrode: $\mathrm{pH} 1.07$ and $7 \cdot 01$ delivered by Synectics). Calibration was performed by the same member of the nursery staff, chosen at random $(\mathrm{n}: 8)$. Calibration with the antimony electrode was performed as recommended by the company, with both the antimony and the cutaneous reference electrode in the calibration fluid; the reference electrode used was recommended and delivered by Synectics. Calibration with the glass electrode was performed as recommended for glass electrodes with the reference electrode on the skin of the patient. When using the Memolog the probes were calibrated beforehand, to standardise the measurement, and after the recording to exclude a possible drift. When using the Synectics equipment, calibration was performed only before the investigation. The temperature of the calibration fluid was that of the environment $\left(19\right.$ to $\left.21^{\circ} \mathrm{C}\right)$. Should the response time have been over 30

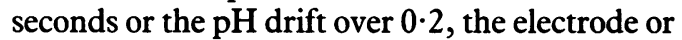
the recording, or both, would have been rejected. This did not happen, however; there was no drop out. There was no 'age limit' for the glass electrodes but the antimony electrodes were rejected after five recordings, as suggested by the manufacturers.

The read out of data recorded with the Memolog was performed with an Apple IIe computer, with software developed by our team..$^{9}$ The read out of data recorded with the Digitrapper was performed with an IBM computer using the program provided by the company (EsopHagram, Gastrosoft Inc). A major difference between both programs is the temperature correcting factor that can be (and was) introduced in the Synectics program and not in ours. (The latter may possibly be of importance since the response time of the electrode is dependent on the temperature). For both systems a reflux episode was considered to start whenever the $\mathrm{pH}$ was $<4$ and to stop if the $\mathrm{pH}$ rose $>4$. The same parameters were analysed as follows: the percentage of the investigation time with a $\mathrm{pH}<4$ (reflux index); the number of episodes with a $\mathrm{pH}$ under 4 ; and the number of

TABLE II Pearson correlation coefficients and 95\% confidence intervals $(C I)$

\begin{tabular}{|c|c|c|c|c|c|c|c|}
\hline \multirow[b]{2}{*}{ Group } & \multirow[b]{2}{*}{ no } & \multicolumn{2}{|c|}{ Reflex index } & \multicolumn{2}{|c|}{$\begin{array}{l}\text { No episodes } \\
p H<4\end{array}$} & \multicolumn{2}{|c|}{$\begin{array}{l}\text { No episodes } p H \\
<4 \text { lasting } \\
>5 \text { min }\end{array}$} \\
\hline & & $r$ & $95 \% C I$ & $r$ & $95 \% C I$ & $r$ & $95 \% C I$ \\
\hline $\begin{array}{l}1 \\
2 \\
3 \\
4 \\
5 \\
6\end{array}$ & $\begin{array}{r}8 \\
8 \\
10 \\
12 \\
32 \\
18 \\
42 \\
130\end{array}$ & $\begin{array}{l}1.00 \\
0.99 \\
0.98 \\
0.83 \\
0.90 \\
0.70 \\
0.55\end{array}$ & $\begin{array}{l}0.95-1.00 \\
0.95-1.00 \\
0.94-1.00 \\
0.77-0.98 \\
0.80-0.95 \\
0.35-0.88 \\
0.29-0.73\end{array}$ & $\begin{array}{l}0.95 \\
0.79 \\
0 \cdot 82 \\
0.73 \\
0.88 \\
0.72 \\
0.70\end{array}$ & $\begin{array}{l}0 \cdot 76-0.99 \\
0 \cdot 21-0.96 \\
0.57-0.94 \\
0 \cdot 27-0.92 \\
0 \cdot 77-0.94 \\
0.38-0.89 \\
0.50-0.83\end{array}$ & $\begin{array}{l}0.99 \\
0.98 \\
0.97 \\
0.94 \\
0.72 \\
0.42 \\
0.51\end{array}$ & $\begin{array}{l}0.95-1.00 \\
0.90-0.99 \\
0.89-0.99 \\
0.52-0.96 \\
0.50-0.86 \\
0.06-0.74 \\
0.24-0.71\end{array}$ \\
\hline
\end{tabular}

Group $1=1$ recording device $($ Memolog $) / 2$ glass electrodes; group $2=$ recording devices (Memolog) $/ 2$ glass electrodes; group $3=2$ recording devices (Digitrapper) $/ 2$ glass electrodes; group $4=2$ recording devices ( 2 companies)/2 glass electrodes; group $5=2$ recording devices (Digitrapper) $/ 2$ antimony electrodes; group $6=2$ recording devices (Digitrapper) $/ 1$ antimony and 1 glass electrode; group $7=2$ recording devices ( 2 companies) $/ 1$ antimony and 1 glass electrode. episodes lasting longer than five minutes. (The definition of reflux index in our computer program was different from that in the Synectics program in which 'reflux index' stands for the number of reflux episodes per hour.)

\section{METHODS}

Seven different groups were studied. On all infants 'double' continuous 24 hour oesophageal $\mathrm{pH}$ monitoring was performed. The electrodes were introduced transnasally. The positioning of the $\mathrm{pH}$ sensitive points of the electrodes in exactly the same location in the middle third of the oesophagus, was controlled by fluoroscopy.

\section{Group 1}

'Double' $\mathrm{pH}$ monitoring was performed on eight infants using one Memolog memory unit (out of eight) connected to two $\mathrm{pH}$ modules (out of 10), both chosen at random." Each module was connected to one glass electrode.

This group was needed to study the reproducibility of data recorded with a glass electrode: the single variable in this group was the use of two electrodes.

\section{Group 2}

Two 'single' $\mathrm{pH}$ monitorings were performed on eight other infants using two independently recording Memolog units, each connected to one glass electrode. Eight Memologs, eight $\mathrm{pH}$ modules, and eight microelectrodes were used. The calibrating nurse, memory unit, and ' $\mathrm{pH}$ module electrode' unit were selected at random.

The difference between groups 1 and 2 was the use of one or two recording devices of the same company. The goal was to study whether the recording apparatus itself influenced the data.

\section{Group 3}

Two independently recording Digitrappers, each connected to one glass electrode, were used on 10 infants. Five Digitrappers and five electrodes were used. The calibrating person and 'Digitrapper and electrode' unit were chosen at random.

The difference between groups 3 and 2 was the use of Digitrappers instead of memologs. Group 3 was designed to study the reliability of the Digitrapper MKII recording devices in clinical routine.

\section{Group 4}

In this group, two $\mathrm{pH}$ recording systems from different companies were tested on 12 infants: one Memolog (out of eight) and one Digitrapper (out of five) each connected to a glass electrode.

The aim of this group was to analyse whether data recorded at different sampling rates with devices from different companies were comparable.

\section{Group 5}

This group is comparable with group 2 . Thirty 
TABLE III Values of the reflux index (\% time with a pH<4)

\begin{tabular}{|c|c|c|c|c|c|c|}
\hline \multirow[b]{2}{*}{ Group } & \multicolumn{3}{|c|}{ Electrode I } & \multicolumn{2}{|c|}{ Electrode 2} & \multirow{2}{*}{$\begin{array}{l}\text { No difference } \\
\text { electrode } 1 / 2\end{array}$} \\
\hline & No & Type & Mean (range) & Type & Mean (range) & \\
\hline $\begin{array}{l}1 \\
2 \\
3 \\
4 \\
5 \\
6 \\
7\end{array}$ & $\begin{array}{r}8 \\
8 \\
10 \\
12 \\
32 \\
18 \\
42\end{array}$ & $\begin{array}{l}\mathrm{G} \\
\mathrm{G} \\
\mathrm{G} \\
\mathrm{G} \\
\mathrm{AM} \\
\mathrm{AM} \\
\mathrm{AM}\end{array}$ & $\begin{array}{r}12 \cdot 12(0-58) \\
14 \cdot 00(2-30) \\
13 \cdot 14(0-35) \\
7 \cdot 17(1-15) \\
4 \cdot 85(0-23) \\
5 \cdot 35(0-24) \\
4 \cdot 41(0-14)\end{array}$ & $\begin{array}{l}\mathrm{G} \\
\mathrm{G} \\
\mathrm{G} \\
\mathrm{G} \\
\mathrm{AM} \\
\mathrm{G} \\
\mathrm{G}\end{array}$ & $\begin{array}{r}12 \cdot 12(0-55) \\
14 \cdot 50(4-32) \\
13 \cdot 07(0-37) \\
6 \cdot 75(1-12) \\
5 \cdot 04(0-24) \\
9 \cdot 22(0-27) \\
12 \cdot 43(0-42)\end{array}$ & $\begin{array}{l}5(63 \%) \\
2(25 \%) \\
4(40 \%) \\
4(33 \%) \\
8(25 \%) \\
2(11 \%) \\
3(7 \%)\end{array}$ \\
\hline
\end{tabular}

Type of electrode; $\mathrm{G}=$ glass electrode; $\mathrm{AM}=$ antimony electrode.

Group $1=1$ recording device (Memolog)/2 glass electrodes; group $2=2$ recording devices $($ Memolog) $/ 2$ glass electrodes; group $3=2$ recording devices (Digitrapper) $/ 2$ glass electrodes; group $4=2$ recording devices ( 2 companies) $/ 2$ glass electrodes; group $5=2$ recording devices (Digitrapper) $/ 2$ antimony electrodes; group $6=2$ recording devices (Digitrapper) $/ 1$ antimony and 1 glass electrode; group $7=2$ recording devices ( 2 companies)/l antimony and 1 glass electrode.

two infants were examined with two independently recording Digitrappers, each connected to one antimony electrode.

In this group we analysed the reproducibility of the data recorded with antimony electrodes. We investigated whether data recorded with one antimony-Digitrapper unit were comparable with data recorded with a similar recording system? Group 5 differed from group 3 in the use of antimony electrodes instead of glass electrodes.

\section{Group 6}

Eighteen infants were investigated using simultaneously one Digitrapper connected to an antimony electrode and another Digitrapper connected to a glass electrode. Temperature corrections were made to analyse the data, as was suggested by the company.

This group was of major importance, since their results would answer the question of whether data recorded with an antimony electrode are comparable with those recorded with a glass electrode.

\section{Group 7}

A Digitrapper connected to an antimony electrode was used simultaneously with a Memolog connected to a glass electrode in 42 infants. In this group different electrodes and different recording devices are compared.

\section{STATISTICS}

Supposing the data do not depend on the recording devices or the probes, there will be no difference between the two groups of data that

TABLE IV Mean differences and lines of equality regarding the reflux index

\begin{tabular}{lcr}
\hline Group & Mean $(2 S D)$ difference el $1-2$ & No \\
\hline 1 & $0.00(2 \cdot 80)$ & 7 \\
2 & $-0.50(3 \cdot 20)$ & 8 \\
3 & $0 \cdot 48(3.43)$ & 9 \\
4 & $0 \cdot 50(3 \cdot 20)$ & 11 \\
5 & $-0 \cdot 19(4 \cdot 76)$ & 31 \\
6 & $-3 \cdot 87(11 \cdot 36)$ & 17 \\
7 & $-8.02(17 \cdot 72)$ & 41 \\
\hline
\end{tabular}

Mean (2 SD) difference el $1-2=$ mean difference $(2 \mathrm{SD}$, limits of agreement, or $95 \%$ confidence intervals) of the data registered with electrode 1 compared with the data recorded with electrode 2 . wo=the number of infants with a difference between electrode 1 No=the number of infants with a difference between electrode
and 2 within the limits of agreement for definition of groups see Tables II or III. are compared in each group. Therefore Pearson corelation coefficients were calculated. When there is no difference the coefficient is 1 ; the larger the differences, the smaller the coefficient. In addition confidence limits were calculated for the Pearson correlation coefficient.

Graphs, relating the mean differences of the data to the best estimation of the true value, allow the evaluation of any relation between measurement error and the true value. ${ }^{12}$ The limits of agreement show the size of the variability of the differences observed between corresponding observations. ${ }^{12}$

\section{Results}

The Pearson correlation coefficient ranged from 1.00 to 0.42 (Table II), or from excellent to extremely poor. The very poor correlation regarding the number of episodes lasting longer than five minutes is related to the relatively small incidence of this parameter in each examination. As a consequence small differences between the data have a great repercussion on the correlation coefficient.

Emphasis is placed on the reflux index, since this parameter is the result of the summation of the duration of all episodes with a $\mathrm{pH}<4$, divided by the total duration of the examination. Therefore this parameter is closely related to the others. The mean and ranges of the reflux index in the different groups are listed in Table III. Differences increase if two types of electrodes (glass and antimony) are compared.

The correlation between data recorded with glass electrodes and recording devices of one company (two glass electrodes/one or two Memologs/two Digitrappers) is excellent (groups 1, 2 and 3: 1.00, 0.99 and 0.98). The correlation coefficient in group 5 (two Digitrappers, two antimony electrodes) is 0.90 . This coefficient is still excellent, but certainly lower when compared with the 0.99 and 0.98 of groups 2 and 3 (two Digitrappers, two Memologs, two glass electrodes). Moreover, the decrease in correlation for the reflux index from 0.98 (group 3) to 0.90 (group 5) implies a decrease of correlation for the number of long lasting episodes from 0.97 (group 3) to 0.72 (group 5). A poor coefficient of 0.72 is found for the number of long lasting reflux episodes in group 5 , evaluating the reliability of antimony electrodes.

When recording devices of different companies, but still with glass electrodes, are used, the Pearson coefficient for the reflux index remains high, but decreases to 0.93 . When different recording devices are used with different electrodes (glass and antimony), however, the coefficient decreases to $0 \cdot 55$. Different electrodes with one type of recording apparatus result in a coefficient in between $(0 \cdot 70)$.

The reliability of data recorded with glass microelectrodes is affected by the small number of patients included in these groups (respectively eight, eight, 10, and 12) compared with the larger numbers in the groups in which antimony electrodes were used (respectively 32, 18, and 42). Differences in small groups have a much greater effect on correlation coefficients than identical differences in large groups. If data are 
in no way dependent on the equipment, the 'limits of agreement' should be zero since the only differences in the study design were equipment related. ${ }^{12}$

The mean differences are listed in Table IV, together with the limits of agreement (which are the $95 \%$ confidence intervals of the mean differences-or 2 SDs calculated on the mean difference). Ninety five per cent of the differences are expected to be within the range of the limits of agreement (mean differences (2 SD)), (definition of the repeatability coefficient adapted by the British Standards Institution). ${ }^{13}$ The smaller the limits of agreement, the more the data are comparable. According to this definition, data in Table IV are classified from high to low comparability. The limits of agreement between data recorded with two glass electrodes and recording devices of one or two companies are extremely narrow, suggesting a close relation between the data. Data recorded with two antimony electrodes (group 5) have larger limits of agreement than data recorded with two glass electrodes (groups 1, 2, 3, and 4). The limits of agreement are very large in groups 6 and 7, comparing a glass to an antimony electrode.

\section{Discussion}

Continuous oesophageal $\mathrm{pH}$ monitoring is nowadays regarded as a reliable aid in the diagnosis of gastro-oesophageal reflux disease. Although the basic principle of the investigation technique is quite simple, the data registered depend on numerous factors. Patient related factors are multifarious-for example feeding, position, activity - and are not discussed any further here. Although essential for biomedical tests, however, the influence of a number of technique related factors have not been thoroughly evaluated.

When intraluminal $\mathrm{pH}$ recording was first introduced, $\mathrm{pH}$ tracings were written on stationary strip chart recorder in in-patients. ${ }^{14}$ Most portable recorders are equipped with solid state memories. ${ }^{15}$ An accuracy of $1 \%$ is guaranteed for most of the recording devices available because of the commonly used eight bit (or more) data format. Since these recording devices are, in fact, nothing more than 'memory boxes,' it can be expected that they do not influence the data. Statistical tests on groups 2, 3, and 4 suggest that the results obtained with different recording devices but with the same type of electrode are comparable.

One factor that has not, up to now, been thoroughly evaluated is the influence of the type or age of the $\mathrm{pH}$ electrode. Glass electrodes can be used up to 50 times, but their response time becomes longer through use. This may be an important factor in research, but its influence seems negligible for diagnostic investigations since there was no age limit for the electrodes used (except a response time of $>30$ seconds), and correlation factors were extremely high in group 1 (two electrodes connected to one recording device).

Glass electrodes proved to be preferable to antimony electrodes in a laboratory setting. ${ }^{2}$
Nevertheless antimony electrodes have been proposed for paediatric use because of their small diameter. ${ }^{3-6}$ The glass microelectrode has nearly an identical diameter, however. Both have the same inconvenience in that they require a cutaneous $\mathrm{Ag} / \mathrm{AgCl}$ reference electrode. ${ }^{2}$ It has been suggested that differences in recorded $\mathrm{pH}$ are related to the use of a cutaneous as opposed to an intraluminal reference electrode. This effect has been attributed to transmucosal potential differences. Different junctional potentials at the skin reference electrode and intraluminal reference electrode may also contribute to this discrepancy. ${ }^{216}$ The possible inaccuracies can also be the result of loss of skin contact and local changes in the composition of the ions because of perspiration. ${ }^{17}$ Skin potential differences between the infants are factors that might influence the accuracy of the $\mathrm{pH}$ recording. Since the limits of agreement in group 1 (two electrodes, one recording device) are extremely narrow, however, these potential differences do not seem to be clinically relevant. Therefore, we believe that the differences between the glass and antimony electrodes (which were also reported by Gignoux ${ }^{17}$ ) are related to characteristics of the electrode and not to the use of the external reference electrode as was suggested by Gignoux. ${ }^{17}$

Both antimony and glass electrodes are commonly used. ${ }^{2-615}$ The accuracy (the minimum variation of the $\mathrm{pH}$ received by the electrode) and the sensitivity (that is $\mathrm{mV}$ response per $\mathrm{pH}$ unit) of the glass electrode are better, however, than for the metal electrode. ${ }^{18-20}$ In addition, the response time of the glass electrode is much faster than that of the metal electrode. ${ }^{2}$ Practical points are the price and the lifespan of the electrode. Comparison of prices is difficult, however, since the same electrode can cost different amounts in different countries: in The Netherlands, the cost of an antimony electrode is £65 approximately and in Belgium approximately £35. Five recordings of 24 hours each are guaranteed by Synectics as the lifespan for reliable registrations. With the microelectrode (cost in Belgium approximately £335) 40 to 60 complete tests can be performed if the electrode is handled properly. With antimony electrodes in which the electrical potential is determined by a process of corrosion, stabilisation takes more time with the increasing corrosion of the electrode. ${ }^{21}$ Reactions with ions other than $\mathrm{H}+$ are possible. For optimal patient tolerance, the stiffness of the probe should be minimal, enhancing an easy introduction and tolerance of the probe during registration. Although the glass electrode is of the same calibre as the antimony one, the latter is less stiff. If, however, the glass electrode is introduced via a supple guide already in situ, its rigidity is not of real inconvenience.

Antimony electrodes have been compared with glass electrodes in only a few studies. In an in vitro study by $\mathrm{McLaughlan},{ }^{2}$ glass electrodes proved to be superior to antimony. Three abstracts were published on the subject in 1988. ${ }^{22-24}$ A Swedish study showed no difference between antimony and glass (Ingold) electrodes during intragastric $\mathrm{pH}$ monitoring. ${ }^{.2}$ In another Swedish study oesophageal $\mathrm{pH}$ monitoring was 
performed on eight patients and gastric monitoring on three, showing small differences between both recordings. ${ }^{23}$ The correlation coefficient for the reflux index between the data recorded with the antimony electrode and those with glass probe (Radiometer) was $0.98 .{ }^{23}$ In a German study (15 patients) it was shown that mean intragastric $\mathrm{pH}$ recordings were significantly lower with a glass electrode (Ingold) compared with an antimony probe. ${ }^{24}$ These data were confirmed by Gignoux et $a^{13}$; during a three hour postprandial period, the mean percentage of time that the $\mathrm{pH}$ was $<4$ was $8 \%$ with a glass electrode compared with $5.9 \%$ with an antimony electrode. In our study, glass and antimony electrodes are compared in groups 6 and 7. The percentage of time that the $\mathrm{pH}$ was $<4$ was higher with the glass electrode, as was to be expected since the reflux index was higher for this electrode.

The temperature dependency of antimony is such that a difference of $0.55 \mathrm{pH}$ unit exists between readings at $37^{\circ} \mathrm{C}$ and $22^{\circ} \mathrm{C}$, compared with a difference of only $0.05 \mathrm{pH}$ unit for glass. ${ }^{19}$ This has to be considered when group 6 (antimony and glass probe both connected to a Digitrapper) and group 7 (an antimony connected to a Digitrapper, and a glass probe connected to a Memolog) are compared. A correcting factor, taking the difference of adaptation to temperature changes into account, is included in the Synectics program. This was not foreseen in the program we developed. Nevertheless, the limits of agreement are large and the correlation coefficient is low $(r: 0 \cdot 70$ for the reflux index) when data, recorded with both electrodes connected to a Digitrapper and read out with the Synectics program are compared (group 6).

Data are not influenced by the recording device itself provided glass electrodes are used. Data recorded with glass electrodes are very reproducible ( $\mathrm{r}: 1.00,0.99,0.98$ for the reflux index). With antimony electrodes, the correlation coefficients are lower and the limits of agreement larger, although still acceptable ( $r: 0.90$ for the reflux index). Nevertheless, data recorded with antimony electrodes are not comparable with those recorded with glass electrodes. It has been found that the mean $\mathrm{pH}$ recorded with antimony electrodes is higher than that recorded with glass electrodes, and this despite the application of temperature correcting factors. Since the cost of both electrodes is more or less equal and glass electrodes seem to be better, we propose to use glass microelectrodes rather than antimony probes in paediatrics.
1 Bennett JR. pH measurement in the oesophagus. In: Tytgat GNJ, ed. Baillières Clinical Gastroenterology. Oxford: Alden Press, 1987: 747-68.

2 McLaughlan G, Rawlings JM, Lucas ML, McCloy RF, Crean $\mathrm{GP}$, McColl KEL. Electrodes for 24 hour $\mathrm{pH}$ monitoring comparative study. Gut 1987; 28: 935-9.

3 Ask P, Edwall G. Johansson KE, Tibbling L. On the use of monocrystalline antimony $\mathrm{pH}$ electrodes in gastro-oesophageal function disorders. Med Biol Eng Comput 1982; 20 383-9.

4 de Caestecker JS. Twenty-four-hour oesophageal pH monitoring: advances and controversies. Neth $\mathcal{F}$ Med 1989; 34: S20-S39.

5 Klinkenberg-Knol EC, Ogilvie AC, Meuwissen SGM. Twentyfour-hour ambulatory oesophageal $\mathrm{pH}$ monitoring: experence in the Netherlands. Neth F Med 1989; 34: S40-S54.

6 Masliah C, Galmiche JP, Cloarec D, Gerard P, Czernichow P, Bruley des Varannes S. Twenty-four hour oesophageal $\mathrm{pH}$ monitoring in infants with suspected gastro-oesophagea reflux disease: relationships with symptoms, endoscopy and evolution. Eur $\mathcal{F}$ Gastroenterol Hepatol 1990; 2: 137-42.

7 Herbst JJ, Minton SD, Book LS. Gastroesophageal reflux causing respiratory distress and apnea in newborn infants. 7 Pediatr 1979; 95: 763-8.

8 Menon AP, Schefft GL, Thoch BT. Apnea associated with regurgitation in infants. $\mathcal{F}$ Pediatr 1985; 106: 625-9.

9 Vandenplas $\mathrm{Y}$, Sacre L. Continuous 24 hour esophageal $\mathrm{pH}$ monitoring in 285 asymptomatic infants $0-15$ months old. $f$ Pediatr Gastroenterol Nutr 1987; 6: 220-4.

10 Lepoudre R, Vandenplas Y, Sacre L, Sonck W, Kuyk S. A commercialized program on Apple-computer for a $24 \mathrm{H}$ continuous intraesophageal $\mathrm{pH}$ monitoring. Lecture Notes in Medical Informatics; Medical Informatics Europe 85 , Proceedings, Helsinki, Finland 1985; 658-662 Edope 85, DHF, Grönroor P, Tero-Pellika R, O'Moore R. SpringerVerlag.

11 Vandenplas Y, Goyvaerts H, Helven R, Sacre L. Do esophageal pH monitoring data depend on recording equipment and probes? F Pediatr Gastroenterol Nutr 1990; 10: 322-6.

12 Bland JM, Altman DG. Statistical methods for assessing agreement between two methods of clinical measurement. Lancet 1988; 307-10.

13 British Standards Institution. Precision of test methods. I Guide for the determination and reproducibility for standard test method (BS 5497, part 1). London: BSI, 1979.

14 Johnson LF, DeMeester TR. 24-H pH monitoring of the distal esophagus. A quantitative measure of gastro-esophageal reflux. Am $\mathcal{F}$ Gastroenterol 1974, 6: 325-32.

15 Emde C, Garner A, Blum AL. Technical aspects of intraluminal $\mathrm{pH}$ metry in man: current status and recommendations. Gut 1987; 28: 1177-88.

16 Read NW, Fordtran JS. The role of intraluminal junction potentials in the generation of gastric potential difference in man. Gastroenterology 1979; 76: 932-8.

17 Gignoux C, Bonnet-Eymard PO, Hostein J, Fournet J Enregistrement ambulatoire du pH eosophagien pendant 24 heures dans une population de 27 témoins: analyse des facteurs techniques et méthodologiques influençant les résultats. Gastroenterol Clin Biol 1987; 11: 17-23.

18 Plambeck JA. Electroanalytical chemistry: basic principles and applications. New York: John Wiley \& Sons, 1982: 147-91.

19 Ask P, Edwall G, Johansson KE. Accuracy and choice of procedures in 24-hour $\mathrm{pH}$ monitoring with monocrystalline electrodes. Med Biol Eng Comput 1982; 20: 383-9.

20 Emde C, Hopert R, Riecken EO. Basic principles of $\mathrm{pH}$ registration. Neth f Med 1989; 34: S3-9.

21 Bruley des Varannes S, Ducrotte P, Galmiche JP. How to choose an ambulatory $\mathrm{pH}$ monitoring system? Gastroenterol Clin Biol 1987; 11: 382-6.

22 Anderson J, Ström M. Identical 24-hour intragastric pH profiles obtained with monocristalline antimony and glass electrodes. Gastroenterol Int 1988; 1 (suppl 1).

23 Johnsson F, Joelsson B. Comparison between electrodes for extended pH monitoring. Gastroenterol Int 1988; 1 (suppl 1)

24 Beholz S, Wagner S, Freise J, Schmidt FW. Comparison of long-term-ambulatory $\mathrm{pH}$-monitoring performed with antimony and combined glass electrodes. Gastroenterol In 1988; 1 (suppl 1). 